\title{
SP01-03
}

\section{Selection of cassava accessions with multiple resistance to pathogens associated with root rot disease}

Eder Jorge de Oliveira ${ }^{1 *}$, Saulo Alves Santos de Oliveira ${ }^{1}$, Sandielle Araújo Vilas Boas ${ }^{2}$, Camila Santiago Hohenfeld ${ }^{2}$ and Vanderlei da Silva Santos ${ }^{1}$

${ }^{1}$ Embrapa Mandioca e Fruticultura, Rua da Embrapa, Caixa Postal 007, Zip Code 44380-000 Cruz das Almas, BA, Brazil. ${ }^{2}$ Universidade Federal do Recôncavo da Bahia, Campus Cruz das Almas, Zip Code 44380-000 Cruz das Almas, BA, Brazil.

* eder.oliveira@embrapa.br, Registrant ID\# 2158

The cassava root rot disease (CRRD) severely affects productivity in several countries. The objective of this study was to estimate genetic parameters and to identify multiple resistance sources against pathogens associated with CRRD. For this, the symptoms caused by Fusarium spp., Phytophthora spp., and Botryosphaeriaceae species in peel and pulp from the roots were evaluated in 277 accessions using a whole tuber inoculation method. Genotypic data for resistance to pathogens were obtained by REML/BLUP (restricted maximum likelihood / best linear unbiased predictor). The classic selection index (Cl), multiplicative (MI), and sum of ranks (SRI) were used to identify the accessions with multiple resistance. For all pathogens, the environmental variance $\left(\sigma_{e}^{2}\right)$ was the most important component. Individual plant heritability ( $h_{g}^{2}$ ) was of low magnitude for most of pathogens (ranged from $0.16 \pm 0.02$ to $0.31 \pm 0.03$ for Fusarium spp., in peel and pulp, respectively). The distribution of CRRD symptoms indicated the presence of quantitative inheritance. The direct selection of the 15 more resistant accessions based on the genotypic predicted values result in high reductions of disease (>50\%). However, there was a low coincidence of the most resistant accessions for each pathogen and the different parts of the roots (peel and pulp). The $\mathrm{Cl}$ and $\mathrm{MI}$ were the most promising compared to the SRI to ensure high and balanced symptoms reductions for each pathogen. Understanding the genetic basis of resistance to CRRD and the identification of sources with multiple resistances may be useful in various management strategies to control the disease. 